\title{
EL REGLAMENTO DE PATRIMONIO DE LOS ENTES LOCALES DE CATALUÑA
}

\author{
POR \\ LUIS CHACÓN ORTEGA
}

\begin{abstract}
SUMARIO: I. INTROdUCCIÓN.-II. PLANTEAMIENTO Y ESTRUCTURA.-III. El PATRIMONIO de LOS ENTES loCALES: 3.1. Concepto de patrimonio. 3.2. Clasificación de los bienies. 3.3. Patrimonios especiales. 3.4. Alteración de la calificación jurídica de los bienes.-IV. Tráfico juRídico de los bienes: 4.1. Adquisición. 4.2. Enajenación. 4.3. Cesión.-V. UTILIZACIÓN Y APROVECHAMIENTO DE LOS BIENES: 5.1. Utilización de los bienes de dominio público. 5.2. Utilización de los bienes patrimoniales.-VI. CONSERVACIÓN, PROTECCIÓN Y DEFENSA DE LOS BIENES: 6.1. Inventario. 6.2. Inscripción en el Registro. 6.3 La acción investigadora. 6.4. Recuperación de oficio. 6.5 Desahucio administrativo. 6.6. Ejercicio de acciones.
\end{abstract}

\section{ABREVIATURAS UTILIZADAS}

CE: Constitución Española de 1978.

CC: Código Civil de 1889.

DOG: Diario Oficial de la Generalitat.

LBRL: Ley Reguladora de las Bases de Régimen Local 7/1985, de 2 de abril.

LPA: Ley de Procedimiento Administrativo de 17 de julio de 1958 :

LPE: Ley del Patrimonio del Estado, texto articulado de 15 de abril de 1964.

LS: Ley de Régimen del Suelo y Ordenación Urbana, texto refundido aprobado por Real Decreto 1346/1976, de 9 de abril.

LLMC: Ley Municipal y de Régimen Local de Cataluña 8/1987, de 15 de abril.

RB: Reglamento de Bienes de las Entidades Locales, aprobado por Real Decreto $1372 / 1986$, de 13 de junio.

RP: Reglamento del Patrimonio de los Entes Locales, aprobado por Decreto de la Generalitat 336/1988, de 17 de octubre.

\section{INTRODUCCION}

Fernando Albi, en la introducción a su ya clásico libro «Tratado de los Modos de Gestión de los Entes Locales», dice que «debiera ser más frecuente que quienes colaboraron técnicamente con los organismos oficiales en la creación legal, expusieran después los resultados de su experiencia. «Ello reportará, indudablemente, una gran utilidad:»

Nosotros hemos colaborado en la redacción del Reglamento de Patrimonio de los Entes Locales y creemos que puede ser útil lo que manifiesta el entrañable compañero; pero, en definitiva, como él mismo señala, lo que interesa no es lo que nosotros quisimos decir, ni aun lo que dijimos, sino lo que en realidad consigna el texto 
reglamentario, ya impersonalizado, y lo que resulte de su posterior interpretación auténtica, jurisprudencial y científica.

Nuestras reflexiones nacen de una experiencia inicial y quisiéramos que fuesen unas más de las reflexiones y comentarios que pudiesen surgir y que nos ayudasen al conocimiento y aplicación del RP, que ha iniciado su andadura legal en el DOG número 1.076. de 2 de diciembre de 1988.

Se ha dicho del RP que es un reglamento técnico (1), incluso ha sido calificado de "alto nivel técnico» (2). Esto es cierto, lo de técnico. El RP es una norma escrita dictada por la Generalitat, que tiene su límite en la propia ley que desarrolla. Es, pues, un reglamento ejecutivo, circunscrito al ámbito de Cataluña.

Pero en el RP destaca también una notable preocupación social que late a lo largo de su articulado, vertebrada como una vena que aflora no exenta de un cierto romanticismo, y ello más allá de la letra de la ley y de la frialdad de lo "técnico".

En efecto, en el artículo 8.2 se dice: «Los bienes patrimoniales están en el comercio jurídico, pueden procurar directa o indirectamente la satisfacción de necesidades ajectivas»..., lo cual está apuntando ya su posible utilización social.

En el artículo 72, después de transcribir el artículo 203 de la LLMC, que nos habla de la administración de los bienes conforme a criterios de máxima rentabilidad, en las condiciones usuales de la práctica civil y mercantil, el RP, en su apartado 3, nos dice:

72.3 «No obstante lo que prevé el apartado anterior, los entes locales pueden valorar motivaciones de prestación de servicios sociales, promoción y reinserción sociales, actividades culturales y deportivas, promoción urbanistica, fomento del turismo, ocupación del tiempo libre u otras análogas que hagan prevalecer una rentabilidad social por encima de la rentabilidad económica.»

Consecuente con esta valoración de lo social, en su artículo 75 regula por primera vez en la Administración local, creemos nosotros, la cesión gratuita del uso de bienes patrimoniales a otras administraciones o entidades públicas o a entidades privadas sin ánimo de lucro que los hayan de destinar a fines de utilidad pública o de interés social, siempre en beneficio de intereses de carácter local.

(1) Informatiu Setmanal, núm. 79, de 25 de desembre, de la FMC, p. 3.

(2) Escrit de la Diputació de Girona núm. 1.451, de 8 d'abril de 1988. 
Siguiendo espigando en su articulado, el 91, referido a los bienes comunales, establece que:

"Los entes locales, de acuerdo con los vecinos titulares de los aprovechamientos y con sujeción a las prescripciones de la legislación sectorial específica, han de procurar la industrialización y la comercialización de los productos de sus bosques comunales y ejercer la iniciativa pública como medida de reactivación económica y fomento de la ocupación.»

Y el artículo 155.2, al regular el desahucio administrativo, establece la posibilidad de la indemnización fijada libremente, por mutuo acuerdo, sin las trabas de las fórmulas preestablecidas en el RB, que encorsetan al ente local y que tan lejos quedaban, por lo general, de la indemnización justa, del precio real.

$Y$ esta misma preocupación late en el artículo 175.2 cuando establece que para la graduación de la responsabilidad se han de tener en cuenta las circunstancias personales y económicas del infractor.

Por último, en su artículo 18, el RP deja aflorar esta vena romántica no exenta de pragmatismo:

18.1 «Los entes locales que tienen en el territorio de su jurisdicción bienes de interés histórico-artístico que no les pertenecen han de procurar, mediante convenios, compatibilizar la titularidad económica privada del bien y su interés cultural.»

18.2 «Se ha de promover la tutela específica del bien para que éste pueda ser objeto de fruición colectiva, sin perjuicio de su titularidad económica.»

En una misma cosa, soporte físico, puede haber distintos bienes, tantos como utilidades. $Y$ así, en el bien histórico-artístico cabe distinguir el bien patrimonial en el sentido de pertenencia económica, $y$ en el bien cultural, como testimonio material de la civilización, que es un bien de fruición colectiva y que es público. Es la tesis del profesor Giannini (3).

En la jerarquía de las normas, el RP sabe que está al pie de los caballos y que no puede hacer más, por eso se limita a ordenar a los entes locales que "han de procurar» compatibilizar ambos bienes, el de pertenencia y el de fruición, dejando como punta de

(3) GARCIA DE ENTERRIA: "Consideración sobre una nueva legislación del patrimonio artistico, histórico y cultural», en REDA, nủm. 39, 1983, pp. 575 y ss. 
lanza la ventana abierta a la iniciativa e imaginación de los entes locales, cada vez más sensibilizados por el hecho sociocultural.

EI RP es, además, respetuoso con la autonomía de los entes locales. Lo que en el RB, en algunos supuestos, precisa de autorización preceptiva de la Comunidad Autónoma, en el RP queda reducido a meros informes no vinculantes. Es también operativo, simplificando trámites, sin merma de la seguridad jurídica, y extendiendo la posibilidad de los informes internos a los servicios jurídicos y no haciéndolos recaer solamente en el secretario e interventor.

El RP tiene algunos preceptos que parecen gratuitos, por innecesarios, tales como los que regulan la adquisición por ocupación, prescripción o expropiación con meras referencias, como no podía ser de otro modo, a las leyes sectoriales. Pero también transcribe los preceptos de la LLMC que desarrolla, y en este afán codificador podría encontrar justificación lo expuesto.

\section{PLANTEAMIENTO Y ESTRUCTURA}

Promulgada la Llei 8/1987, de 15 de abril, Municipal i de Règim Local de Catalunya, el Departament de Governació elabora el proyecto de Reglamento, que aprueba el Consejo Ejecutivo de acuerdo con la habilitación establecida en la disposición final segunda de la meritada ley.

El Reglamento contiene 177 artículos, estructurados en cuatro títulos con las siguientes rúbricas: Título I: El patrimonio de los entes locales. Título II: Tráfico jurídico de los bienes. Título III: Utilización y aprovechamiento de los bienes. Título IV: Conservación, protección y defensa de los bienes.

Estos títulos se dividen en capítulos y algunos en secciones.

El Reglamento (RP) desarrolla la Ley catalana 8/1987, pero la referencia al Reglamento de Bienes de las Entidades Locales de 13 de junio de 1986 (RB) es obligada también, en estas reflexiones, para señalar la diferencia y las novedades que encierra en la labor interpretatoria que abordamos en el presente estudio.

El primer hecho a destacar es la estructuración del RP. A diferencia del Reglamento estatal '(RB), que contiene dos títulos: Bienes y Del desahucio por vía administrativa, dándole una excepcional importancia a esta última institución, que, en suma, como destaca García de Enterría y Tomás Ramón Fernández (4), es una

(4) Garcia de Enterría y tomás-Ramón Fernández: Curso de Derecho Administrativo I, Civitas, año 1975 . 
variedad de la compulsión directa, y por tanto, dentro de la ejecución forzosa, una más de las prerrogativas de los entes locales. El RP parte de una sistemática completamente diferente, hasta el punto de que el desahucio administrativo, por ejemplo, se encuadra en una simple sección, la $4 .^{a}$, dentro del capítulo $V$, dedicado a las «prerrogativas respecto de los bienes».

En efecto, a través de su estructuración, el RP parece marcarnos formalmente un camino a seguir. Lo primero de todo nos define el patrimonio de los entes locales y clasifica los bienes que lo integran, enseñándonos la forma de alterar su calificación jurídica, todo ello en el título $I$.

Sabido esto, en su título II nos dice que estos bienes están en el tráfico jurídico y que pueden ser adquiridos, enajenados 0 cédidos.

Una vez constituido este patrimonio, clasificados sus bienes, tras la adquisición, nos enseña cómo utilizarlos. Utilización que difiere según sean bienes de dominio público o patrimoniales y trocando esta utilización en aprovechamiento cuando se trata de los comunales.

La titularidad de un patrimonio comporta su utilización, incluso su disposición, pero también la necesidad de su conservación, protección y defensa, mediante el inventario, inscripción en el Registro y un ramillete de prerrogativas que son una consecuencia del poder jurídico de la Administración y tienen su justificación en la autotutela que les viene conferida en razón de los fines de interés público que los entes locales cumplen. Todo ello viene regulado en el título IV y último.

El Reglamento, además, incorpora los preceptos de la ley que desarrolla en un afán codificador, sin perjuicio, claro está, de las legislaciones sectoriales y de la legislación civil de carácter general.

\section{EL PATRIMONIO DE LOS ENTES LOCALES}

\subsection{Concepto de patrimonio}

Al referirse al patrimonio, el Reglamento se refiere a todos los bienes y derechos, cualquiera que sea su naturaleza, integrando, pues, los bienes de dominio público y los patrimoniales, a diferencia de la Ley de Patrimonio del Estado, que deja fuera los bienes de uso y servicio público partiendo de un concepto puramente pecuniario.

Esto no es óbice para que en otras normas pueda ser considerado el patrimonio de los entes locales desde el punto de vista 
exclusivamente pecuniario, pero esto a los efectos específicos a que la norma se refiere (5).

EI RP habla de bienes y derechos, excluyendo las acciones, en la línea establecida por el artículo 183 de la LLMC y a diferencia de la LBRL, que en su artículo 79 menciona los bienes, derechos y acciones.

En realidad el RP no excluye nada, lo que hace es sobreentender que si la acción es el medio de pedir la actuación de la ley para la efectividad de un derecho, todo derecho ha de estar protegido por una acción.

El pasivo integra también el patrimonio. Al hablarnos en el apartado $2 .^{\circ}$ del artículo $1 .^{\circ}$ de patrimonio neto, nos está indicando inequivocamente que las obligaciones integran el patrimonio como parte pasiva del mismo.

\subsection{Clasificación de los bienes}

Al clasificar los bienes en tres grupos, se produce una importante novedad, más formal que material, como señala la Comisión Jurídica asesora, pero que no deja de tener su importancia.

Los bienes según el RP son de dominio público, a su vez de uso o servicio público; comunales y patrimoniales.

En la LLMC si bien en el artículo 185 se dice ... «tendrán también esta consideración (de dominio público) los bienes comunales», en el artículo 192 los distingue al decir «los bienes de dominio público y los comunalesi...

EI RP parece aprovechar esta ambigüedad para definirlos como un "tertius genus» puesta la mira última en la Constitución que en el artículo 132.2 los separa netamente al decir: «la ley regulará el Régimen jurídico de los bienes de dominio público $y$ de los comunales"...

El RP hace causa común con el sector mayoritario de la doctrina que considera que los bienes comunales han de separarse nítidamente de los bienes de dominio público, sin perjuicio de tener el mismo régimen jurídico.

(5) Así la Ley 39/1988, de 28 de diciembre, reguladora de las Haciendas locales en su art. 3.2 considera patrimonio de las entidades locales «el constituido por los bienes de su propiedad, asi como los derechos reales o personales de que 73 sean titulares, susceptibles de valoración económica, siempre que unos y otros no se hallen afectos al uso o servicio público». 


\subsection{Patrimonios especiales}

EI RP dentro del Patrimonio, agrupa bajo la rúbrica de especiales los patrimonios del suelo y el histórico-artístico. La independencia del núcleo patrimonial, su legislación específica, los fines diferentes, son las notas clásicas de los patrimonios separados.

\subsection{Alteración de la calificación jurídica de los bienes}

En el capítulo destinado a la alteración de la calificación jurídica de los bienes, es de destacar que en la alteración expresa que requiere expediente, la información pública se reduce a quince días y el voto favorable de la mayoría absoluta sólo en los casos que comporten la desafectación de bienes de dominio público o comunal. El RP prescinde de la necesidad de la urecepción formal») a que se refiere el RB en su artículo 8.3 carente a nuestro juicio de operatividad y que es copia mimética del artículo 123 de la LPE, donde la recepción formal corresponde al Ministerio de Hacienda.

En las afectaciones tácitas, el RP opera con técnica más precisa y en su artículo 24 mantiene la posibilidad de la desafectación de los bienes de dominio público y comunales si durante un período de 25 años no se han utilizado de acuerdo con la afectación prevista.

Nos recuerda el apartado $5 .^{\circ}$ del artículo $8 .^{\circ}$ del RB de 1955 , aunque en el RP se exige el acto formal de la constatación de esta circunstancia por acuerdo del Pleno.

EI RP regula por primera vez, en la Administración local, que sepamos nosotros, las mutaciones demaniales, entendidas como cambios en el estatuto específico al que está sujeto un bien de dominio público, sin perder su naturaleza juridica, bastando el acuerdo del ente local en el que se acredite la oportunidad del cambio. La oportunidad como sabemos es un concepto jurídico indeterminado que arrastra un amplio margen de apreciación para la Administración y que viene a ser, igual que la conveniencia, manifestación de la exigencia de que ésta actúe al servicio de los intereses generales tal como establece el artículo 103.1 de la Constitución.

La sentencia del Tribunal Supremo de 19 de octubre de 1987 considera mutación demanial el cambio de destino de una charcaabrevadero -bien de uso público- en piscina municipal -bien de servicio público-. 


\section{TRAFICO JURIDICO DE LOS BIENES.}

En el título II, el RP aborda la adquisición, la enajenación y la cesión.

\section{Q.8. Adquisicioion}

El RP parte de una fórmula sintética y amplia a la vez al establecer que los bienes y los derechos se pueden adquirir -art. 29- por cualquier título, oneroso o lucrativo, de derecho público o de derecho privado, de acuerdo con lo que establecen las leyes. Huye así tanto de la fórmula del artículo 10 del RB, como de la del artículo 609 del CC, tildadas por la doctrina como incompletos.

En la adquisición a título oneroso el RP se separa de la legislación estatal que atribuye la competencia para adquirir bienes al Pleno de la Corporación -art. 23.1 del TRRL-, y en su artículo 30.2 atribuye al Alcalde la facultad de adquisición de patrimonio, siempre que su cuantía no exceda del 5 por 100 de los recursos ordinarios de su presupuesto, ni del 50 por 100 del límite general aplicable a la contratación directa. Por recursos ordinarios, entiende el RP y así lo establece en el artículo $\$ 1.2$ «los habituales que previenen de operaciones corrientes descartadas las operaciones de crédito, las de capital y los procedentes de contribuciones especiales, de cuotas urbanísticas y de subvenciones finalistas.

La adquisición a título oneroso tiene, en principio, la consideración de contrato privado conforme preceptúa el artículo 262.2, a), de la LLMiC. De aquí que, en cuanto a su preparación y adjudicación se rija por lo dispuesto en las normas que regulan la contratación administrativa y en cuanto a sus efectos y extinción se regirá por las normas de Derecho privado, actuando el Ayuntamiento como una persona más desprovista de sus prerrogativas.

En la adquisición a título oneroso de bienes inmuebles, el RP exige, entre otros requisitos, la valoración pericial, pero sin precisarnos qué criterios se han de exigir para su valoración.

En las adquisiciones por expropiación forzosa y por razones de urbanismo, estos criterios vienen establecidos en las leyes sectoriales respectivas. Fuera de estos casos $y$ ante el silencio del RP. cualquier criterio valorativo, hechd por un perito, creemos nosotros que puede ser válido, si objetiva y motivadamente nos da el valor real del bien que se pretenda adquirir, entendiendo por valor real el valor del mercado que es como enseña Jerónimo Arozamena (6) el

(6) AROZAMENA JERÓNIMO: "Las valoraciones urbanísticas, XVIl", en Temas de Derecho Urbanístico, Universidad de Oviedo, 1980. 
precio que puede obtener un propietario en el caso de venta ordinaria realizada en condiciones normales a un adquiriente cualquiera. Se trata, pues, de obtener una valoración de equidad, el justo precio, en suma la adecuada y justa compensación económica que ha de entenderse como un equilibrio de las prestaciones, precio real, entre el que da y el que recibe.

EI RP regula la adquisición por sucesión administrativa, novedad de la LLMC que regula esta adquisición en sus artículos 190.4 y 200. Y hace una remisión a las leyes sectoriales en determinados modos de adquisición, que relaciona ejemplificativamente: prescripción, ocupación, expropiación forzosa, urbanismo.

La adquisición a título lucrativo, no está sujeta a restricción, pero el RP exige la aceptación expresa del Presidente del ente local, si es incondicional, o la del Pleno si hay condiciones. No hay restricción para adquirir por este modo, «a caballo regalado no le mires el diente», pero la entidad local no está obligada a aceptar lo primero que se le ofrezca; abstracción hecha de las cesiones gratuitas pero obligatorias por imperativo legal como las cesiones de terrenos a que están obligados los propietarios de suelo urbano o urbanizable programado, conforme a la Ley del Suelo.

\subsection{Enajenación}

En el tema de la enajenación y cesión de bienes el RP marca notables diferencias respecto al RB, tanto de forma como de fondo.

En la enajenación, se minimiza a la simple categoría de informe previo no vinculante del Departamento de Gobernación, si el valor del bien excede del 25 por 100 de los recursos ordinarios, lo que en el RB es una previa autorización vinculante. Como acertadamente retrata Pauli (7) se rebaja o suprime el nivel de tutela anatómica y se transforman las autorizaciones en informes previos no vinculantes y superables, aunque sean desfavorables.

La forma de contratación es la subasta y la competencia del Pleno, con la mayoría legal absoluta del número de miembros, si la cuantía del bien excede el 10 por 100 de los recursos ordinarios, con las excepciones del artículo 43 del propio RP.

En la regulación de la permuta -artículo 47- el RP se limita a transcribir literalmente el artículo 194 de la LLMC. EI RB en esta institución es técnicamente más preciso. Mantener la equivalencia de valores es un error. La experiencia pasada nos ha mostrado las enormes dificultades para lograrla. Superar la diferencia de valores por encima, incluso, del 100 por 100 , es desvirtuar la naturaleza de

(7) . PAUL JOAQUIN: «Patrimoni», en La nova organització territorial de Catalunya, Generalitat de Catalunya, 1987. 
una institución que tiene su regulación precisa en el Código Civil. Ciertamente, nos permitiría utilizar más frecuentemente esta figura, pero al establecer solamente la compensación económica pertinente cuando la diferencia es en perjuicio del bien del ente local, es neutralizar todas las posibles ventajas.

Es preciso acreditar la necesidad o conveniencia de efectuarla. Ambos son conceptos jurídicos indeterminados. Necesario no quiere decir obligatorio, sino no superfluo y es un grado más que la conveniencia, no son equivalentes, aunque tienen el denominador común de la actuación al servicio de intereses generales.

Una novedad del RP es la regulación de la permuta de bienes presentes con otros futuros o cuya existencia no es actual, pero puede presumirse realmente.

Junto al clásico ejemplo de permuta de un solar -bien presentepor alguna $o$ algunas de las viviendas que puedan construirse en él, pueden arbitrarse fórmulas más avanzadas, como la permuta de un bien de dominio público por otro privado con aplazamiento de la entrega hasta que se produzca la desafectación, en este sentido el profesor Clavero Arévalo (8).

\subsection{Cesión}

En el tema de la cesión gratuita de bienes patrimoniales, destaca la simplificación del expediente, que no precisa de los dos trámites que en el RB tanto dificultaban las cesiones: el uinforme del interventor de fondos en el que pruebe no haber deuda pendiente de liquidación con cargo al presupuesto» y uel dictamen suscrito por técnico que asevere que los bienes no son necesarios para la entidad local, ni es previsible que lo sean en los diez años inmediatos».

Es difícil encontrar hoy día un Ayuntamiento operativo y dinámico sin deuda pendiente, pero aún con deudas, puede haber montañas de razones que aconsejen esta cesión en aras de una rentabilidad social que prime sobre el tema pecuniario.

El dictamen del técnico ha de acreditar que los bienes no están comprendidos en ningún plan de ordenación, reforma o adaptación que los haga necesarios al ente local y punto. Ahora bien, aseverar que no serán necesarios en los diez años inmediatos, es hacer futurología; máxime, cuando en ese tiempo tres corporaciones pasarán por el ente local. Esto no quiere decir que el dictamen no sea lo más racional y completo posible manejando, teniendo en

(8) Clavero arévalo. Manuel: "La inalienabilidad del dominio público», en raP, núm. 25,1958, p. 37 
cuenta, todos los indicadores posibles: plan de ordenación, planificación, programa de actividades, etc.

Lo que si ha de quedar justificado -art. 49.2 , b) es que la finalidad de la cesión no se puede alcanzar, manteniendo el ente local el dominio o el condominio de los bienes, ni constituyendo sobre éstos algún derecho real.

Obviamente, los bienes cedidos han de ser destinados al uso previsto, en otro caso revierten automáticamente de pleno derecho al patrimonio del ente local cedente. Pero la instrumentación de la figura de la reversión no siempre ha sido fácil, es por ello que el RP exige que en el acuerdo de cesión conste expresamente la mención de la reversión automática de manera que demostrado el no destino del bien al uso previsto, habrá bastante con el acta notarial de constatación de hechos, notificada en forma legal, para que la reversión produzca sus efectos. Esta constancia actúa a manera de cláusula resolutoria.

\section{UTILIZACION Y APROVECHAMIENTO DE LOS BIENES}

\subsection{Utilización de los bienes de dominio público}

A pesar de que la doctrina no ha dudado en calificar como depurada, la clasificación de las diversas formas de utilización, como señala López Pellicer (9) y a la que, por ello, ha llegado a atribuir incluso un cierto valor general, como paradigma o modelo a seguir para analizar abstractamente la problemática de la utilización del dominio público, el RP introduce novedades importantes.

En primer lugar, se suprimen las modalidades de uso normal y anormal, conforme y no conforme con el destino principal del dominio público a que se afecte.

La doctrina se preguntaba si esta distinción estaba realmente justificada (10). Y Rodríguez Moro manifiesta que esta terminología no hará sino producir confusión a la hora de incardinar los casos reales en una u otra categoría (11).

Nosotros hemos mantenido que el uso puede no ser conforme con el destino principal pero si es compatible puede autorizarse sin más distinciones. «Lo importante es, como señala Godfrin Philippe, que las utilizaciones privativas del dominio no deben incomodar la utilización principal del dominio; ellas deben ser, al menos compati-

(9) LÓPEZ PELLICER: «Sobre el uso especial o privativo del dominio público», en Revista de Estudios de la vida local, núm. 216, 1982, p. 148.

(10) GARRIDO FALlA: Tratado de Derecho Administrativo, V, II, 1982, p. 533.

(11) RODRIGUEZ MORO: Los bienes de las Corporaciones Locales, Abella, 1969. 
bles con aquél. No se puede calificar de anormal una utilización compatible. Alli donde no se dé esta compatibilidad, esta utilización debe impedirse o retirarse» (12).

Otra cuestión que resuelve el RP está centrada en el uso privativo que el RB sujeta a concesión administrativa.

El RP distingue: si el uso privativo no comporta la transformación o la modificación del dominio público queda sujeto al otorgamiento de licencia de ocupación; el uso privativo inherente a la afectación de los bienes y el que comporta la transformación o la modificación del dominio público, quedan sujetos a concesión administrativa.

Esto supone una indudable simplificación, ya que la concesión por su naturaleza contractual y estable presenta una cierta complejidad de procedimiento que el RP estima no es necesaria en aquellos supuestos más sencillos en el que el uso privativo se aproxima al uso común especial y en el que basta con una autorización o permiso de policía unilateral y precaria. Licencia de ocupación temporal, dice el artículo 57.2, que origina una situación de posesión precaria esencialmente revocable por razones de interés público con derecho a indemnización, si procede.

La simplificación se acentúa al corresponder al alcalde el otorgamiento de las licencias y al Pleno el de las concesiones.

Dentro del tema del uso privativo el RP exige de manera inequívoca el concurso como forma de adjudicación de la concesión, evitando la ambigüedad del RB que en su artículo 78.2 dice que «las concesiones se otorgarán previa licitación»; pero evitando explicitar que forma de las existentes, incluso parece estar pensando en la subasta, al hablar de adjudicación provisional, trámite que no se da en el concurso - art. 88.3-.

EI RP, igualmente, rechaza de forma inequívoca la posibilidad de derecho de tanteo del peticionario inicial o del titular del proyecto e incluso de las pujas a la llana de ambos si existiere empate en sus proposiciones. La doctrina, -Albi, López Pellicer, Sánchez Isaacha sido frecuentemente crítica con el derecho de tanteo, calificándolo de vieja y viciosa fórmula licitatoria, que se remonta a la legislación de obras públicas de 1877 y 1878, por la que se atribuye una preferencia a determinada persona por el simple hecho de haber confeccionado un proyecto técnico que se pudo adquirir de la misma con sólo pagar su importe. Es, pues, un sobreprecio inútil, un premio que el interés general no requiere, tal como certeramente sentencia Albi (13) que añade que la publicidad y el

(12) Godfrin, PhILIPPE: Droit Administratif des biens, Massor, 1978.

(13) ALBI, FERNANDO: Tratado de los modos de gestión de las Corporaciones Locales, ed. Aguilar, 1960, p. 555. 
secreto de las proposiciones, garantía de toda licitación, caen por su base «si efectuada la apertura se permite por vía de privilegio, a cualquiera de los proponentes alterar su oferta después de conocer la de los restantes licitadores, resultando perfectamente ocioso e inoperante todo el trámite seguido con anterioridad».

\subsection{Utilización de los bienes patrimoniales}

"Los bienes patrimoniales han de ser administrados de acuerdo con el criterio de máxima rentabilidad, en las condiciones usuales de la práctica civil y mercantil, bien directamente por el ente local o por medio de particulares». Pero tras decir esto en su artículo 72.1, que es copia mimética del correlativo de la LLMC admite que los entes locales pueden valorar una rentabilidad social por encima de la rentabilidad económica. Y por primera vez en la administración regula el precario como cesión gratuita del uso de bienes patrimoniales a otras administraciones 0 entidades públicas 0 a entidades privadas sin ánimo de lucro que los hayan de destinar a fines de utilidad pública o de interés social, siempre en beneficio de intereses de carácter local.

Es una realidad patente, fácilmente contestable, que los entes locales ceden el uso gratuito de bienes patrifioniales. Raro es el Municipio que no tiene cedido algún local a entidades culturales, deportivas, benéficas, etc., para celebrar en ellos sus actividades sin cobrar merced por ello. Sin embargo, ni el RB de 1986 ni la Ley Municipal de Catalunya regulan estas cesiones de uso gratuitas. El RP autoriza y regula reglamentariamente lo que en la vida corriente era una práctica habitual por vía de hecho.

Uno de los problemas que plantea la cesión de uso de bienes patrimoniales, es la responsabilidad civil subsidiaria que puede recaer sobre los entes locales, por la posible «relación de dependencia» en que puedan quedar los usuarios respecto del ente cedente, atendida la interpretación amplia que del artículo 22 del Código Penal (14) viene haciendo el Tribunal Supremo; esto es, objetivándolo en el sentido de apreciar que cualquier relación de dependencia supone su aplicación, incluyéndose dentro de dicha relación de dependencia la comisión, el encargo, la encomienda y hasta la simple conformidad y aquiescencia, quedando únicamente

(14) Art. 22 CP: «La responsabilidad subsidiaria que se establece en el artículo anterior será también extensiva a los amos, maestros, personas, entidades, organismos y empresas dedicadas a cualquier género de industria, por los delitos o faltas en que hubiesen incurrido sus criados, discípulos, oficiales, aprendices, empleados o dependientes en el desempeño de sus obligaciones o servicios."

REVISTA DE ESTUDIOS.-11 
fuera la hipótesis de manifiesta oposición o desconocimiento del hecho de la utilización (15).

Para intentar obviar este problema, el RP exige que en el documento de formalización de la cesión conste el reconocimiento explícito y mutuo conforme al cual el precarista no queda en relación de dependencia respecto del ente local cedente, a los efectos del artículo 22 del Código Penal, y que el uso del bien es gratuito y meramente tolerado.

Aún así, no estaría de más la exigencia, en aquellos casos que se prevea un cierto riesgo, de un seguro de responsabilidad civil.

\section{CONSERVACION, PROTECCION Y DEFENSA DE LOS BIENES}

\subsection{El inventario}

La importancia del inventario de bienes es notoria por la conservación y protección que da a los bienes: por lo que tiene de catalogación, de relación ordenada y valorada de esos bienes: por la importante documentación que acumula y porque las certificaciones de sus asientos, por vía de excepción, a falta de título inscribible, es suficiente para la inscripción de los bienes inmuebles no inscritos.

Pero el inventario no sólo es un instrumento de control, sino que puede serlo de gestión en la configuración que le da el RP.

EI RP estructura el inventario consecuente con la clasificación de los bienes que el propio RP hace: Bienes de dominio público, a su vez de uso y servicio público: bienes comunales y bienes patrimoniales. Pero a los epígrafes y subepígrafes cabe añadirles los que la corporación considere oportuno y cabe efectuar desglose y subclasificaciones más detalladas, pudiendo agruparlos por servicios o centros de costos. Además, el inventario se ha de actualizar continuadamente, sin perjuicio de su rectificación y comprobación posteriores.

Entre los bienes que específicamente se mencionan figuran los equipos informáticos, los derechos de propiedad inmaterial y los bienes de uso público -parques y jardines, plazas y viales urbanos, viales no urbanos y otros bienes de uso público-. Inventariar estos bienes de uso público implicará un esfuerzo considerable, pero habrá valido la pena. Pensamos que son, normalmente, estos bienes los que generan los mayores gastos, tanto en las inversiones reales, como en la conservación y reparaciones ordinarias.

(15) Ver mi trabajo «La cesión gratuita del uso de bienes patrimoniales y la responsabilidad. de los entes locales derivadas de estas cesiones», Revista de la Administración Práctica, ed. Bayer Hnos., septiembre 1988. 


\subsection{Inscripción en el Registro}

La obligatoriedad de inscribir los bienes en el Registro de la Propiedad como medio de identificación y defensa frente a terceros, es una consecuencia del deber de conservarlos y protegerlos. La importancia de estas inscripciones deriva de que a todos los efectos legales, se presume que los derechos reales inscritos en el Registro existen y pertenecen a su titular en la forma determinada por el asiento respectivo.

Ahora bien, el RP, respetuoso, como no podría ser de otro modo, con la legislación hipotecaria, deja claro que ni todos los bienes son inscribibles, ni puede elevarse a la categoría de regla general lo que ha de ser una excepción. Los bienes son inscribibles mediante el correspondiente título inscribible de dominio: notarial, judicial o administrativo. Sólo cuando éste falte, es cuando habrá de utilizarse, por vía de excepción, la certificación del inventario que expida el Secretario.

El RP muestra una especial preocupación porque no haya discordancia entre la realidad y el Registro. Y así exige la inscripción de aquellos bienes de dominio público y uso público que por la alteración de la calificación jurídica, adquieran su calidad de inscribibles. $Y$ si ocurre a la inversa y bienes patrimoniales inscritos adquieren la naturaleza de bienes de uso público local se ha de solicitar quede constancia en el Registro de la indisponibilidad de estos bienes mediante nota marginal.

\subsection{La acción investigadora}

La potestad investigadora, como una más de las prerrogativas de los entes locales, es novedad de la LBRL y del RB que al desarrollarla se limita a transcribir casi miméticamente los preceptos del Reglamento para la aplicación de la Ley de Patrimonio del Estado de 15 de abril de 1964.

El RP al regular esta acción se limita a reconocer la facultad de los entes locales de poder investigar en vía administrativa y con audiencia de los interesados, los bienes y derechos que se supongan de su propiedad con la finalidad de determinar su titularidad. Pero huye del procedimiento que regula el RB de obligar al denunciante a que anticipe el importe de los gastos de la investigación que puedan ocasionarse y de darle un premio del 10 por 100 del valor del bien al final.

Nosotros hemos sido críticos en relación a esta acción que de un lado yugula de raíz cualquier deseo honesto de colaboración y, de otro, troca el deber de colaboración normal por un incentivo 
crematístico de dudosos resultados prácticos y morales. Por tanto nos congratulamos del tratamiento dado por nuestro RP a la acción investigadora.

\subsection{Recuperación de oficio}

En la recuperación de oficio, en virtud de la cual los entes locales pueden por sí mismos y en cualquier momento recuperar la posesión de sus bienes de dominio público y los patrimoniales dentro del año a contar del día siguiente al de la fecha en que se ha producido la usurpación, es de destacar la precisión que hace de que es suficiente durante este plazo haber notificado el acuerdo resolutorio. Obviamente, en cualquier caso, es necesario acreditar el hecho de hallarse en posesión administrativa del bien y haber sido perturbado en la mencionada posesión o despojado de ella.

Un tema del máximo interés relacionado con la recuperación de oficio es el de los interdictos contra las actuaciones de los entes locales en esta materia.

Los interdictos son acciones sumarias dirigidas a decidir sobre el hecho de la posesión de un bien sin cuestionar el derecho. El conocimiento de los interdictos corresponde exclusivamente a la jurisdicción ordinaria. La autotutela administrativa que le permite recuperar de oficio la posesión de sus bienes, coloca a los entes locales y a la Administración en general en situación de privilegio que se ve completada con la imposibilidad de que los particulares puedan interponer los interdictos de retener $y$ recobrar frente a esa iniciativa.

Sin embargo, los interdictos se interponen $y$, lo que es más grave, prosperan porque los entes locales actúan por la vía de hecho. Es preciso no salirse de su competencia, no infringir sustancialmente las reglas que gobiernan su actuación.

En la defensa contra los interdictos ha prosperado en ocasiones -las menos- excepcionar que no se ha producido la previa reclamación ante la Corporación, al tratarse de una acción civil.

\subsection{Desahucio administrativo}

La institución del desahucio ad́ministrativo queda simplificada al poder fijarse la indemnización libremente, por mutuo acuerdo, sin quedar encorsetada en el límite que fija el artículo 126.4 del RB y en la fórmula de su artículo 128 que puede no alcanzar, como así suele suceder, el precio justo o precio real, de mercado.

El plazo de cinco meses para desalojar tiene carácter general y rige mientras no se prevea otro especial en la regulación del 
supuesto específico, siendo necesario respetar, en todo caso, los plazos mínimos que señalen las leyes sectoriales. EI RP ha sido consciente con la doctrina sentada por la jurisprudencia.

Por último, el RP entiende que para materializar el desahucio, si el interesado no da su consentimiento se ha de solicitar al Juzgado de Instrucción, la autorización a que hace referencia el artículo 87.2 de la Ley Orgánica. El privilegio de la ejecución forzosa ha quedado fuertemente descafeinado y nuestro RP es consciente de ello $y$ avisa o lo recuerda, para evitar problemas derivados de actuaciones que pueden ser calificadas de allanamiento de morada. No olvidemos que los domicilios son inviolables.

\subsection{Ejercicio de acciones}

Este epígrafe nos plantea una serie de cuestiones de interés.

- Las entidades locales tienen la obligación de ejercitar las acciones que procedan en defensa de sus bienes y derechos. Sin embargo, esta obligatoriedad parece estar en contradicción con lo preceptuado en el artículo 172 del RP que admite que los entes locales pueden allanarse a las demandas judiciales. La tradición jurídica en nuestro país admite la transacción y el arbitraje exigiendo un quórum especial en la adopción de estos acuerdos, pero prohibe el allanamiento, en este sentido el artículo 73 del RB, 35.2 de la JCA, 83 y 84 LPE, etc.

Allanarse consiste en prestar conformidad a la petición contenida en una demanda o en el abandono de una pretensión. El artículo 172 del RP es copia mimética del correlativo de la LLMC.

- Ningún Tribunal, juez o autoridad administrativa puede dictar providencias de embargo, ni tramitar mandamiento de ejecución contra los bienes y los derechos del patrimonio de los entes locales, ni contra sus rentas, frutos o intereses. Este precepto -art. 173.1- es copia mimética del artículo 215 de la LLMC y una constante en todas las Administraciones, tanto estatal como autonómica.

Personalmente no me lo creo. «El ejercicio de la potestad jurisdiccional en todo tipo de procesos, juzgando $y$ haciendo ejecutar lo juzgado, corresponde exclusivamente a los Juzgados y Tribunales», dice el artículo 117.3 de la Constitución, que en su artículo 24 establece que "itodas las personas tienen derecho a obtener la tutela efectiva de los jueces y Tribunales en el ejercicio 
de sus derechos e intereses sin que, en ningún caso, pueda producirse indefensión». Es patente que si ningún Tribunal puede despachar mandamiento de ejecución, ni dictar providencia de embargo, no se produce la tutela efectiva de los jueces y. Tribunales y éstos dejan de ejercitar uno de sus derechos constitucionalmente importantes "ejecutar lo juzgado».

Hay otros muchos argumentos, pero basta lo expuesto para poner en duda la constitucionalidad de este precepto que proviene de la Ley y que repetimos existe en todas las leyes de patrimonio de las Comunidades Autónomas y del Estado.

La doctrina es fuertemente crítica contra la inembargabilidad de los bienes patrimoniales y muchos magistrados de Trabajo están dictando mandamientos de embargo. Ya se ha abierto la veda $y$ continuará. Así tiene que ser, los bienes patrimoniales están en el tráfico jurídico y constituyen una fuente de garantía frente a los acreedores de los entes locales.

- El ejercicio de acciones exige el previo dictamen del Secretario de habilitación nacional 0 , en su caso, de la asesoría jurídica, faltando ambos, de un letrado.

Este precepto viene a resolver el problema que planteaba el artículo 370 de la Ley de 1955, cuando establecía que el acuerdo correspondiente debería ir precedido del dictamen de un letrado $y$ que había generado una jurisprudencia contradictoria, con no pocos problemas para los Ayuntamientos al acompañar los acuerdos solamente con el dictamen del Secretario, aún siendo letrado y declararlos inadmisibles los Tribunales, puesto que había sido convertido en un presupuesto de admisibilidad de la pretensión procesal en lo contencioso-administrativo por el apartado d) del artículo 57 de la LJC.

El problema se centra en si el secretario no licenciado en derecho puede dictaminar. Nosotros hemos defendido que sí. EI RB sólo habla del secretario, el RP matiza secretario de habilitación nacional al que corresponde la función pública de secretaría comprensiva de la fe pública y el asesoramiento legal preceptivo. 